\title{
Distribuição Espacial da Precipitação para a Região Sudeste do Estado de Mato Grosso.
}

\section{Climatic Hydric Potential for the Southeastern Region of the Mato Grosso State, Brazil.}

\author{
José Roberto Temponi de Oliveira ${ }^{1}$ (temponi30@gmail.com) \\ Luciana Mara Temponi de Oliveira ${ }^{2}$ (luciana.temponi@ibge.gov.br) \\ ${ }^{1}$ Departamento de Estatística da UFMT e ${ }^{2}$ Instituto Brasileiro de Geografia e Estatística - IBGE
}

Enviado em Julho 2014: Aceito em: Agosto 2014 Publicado em Novembro 2014

\begin{abstract}
Resumo: O sudeste do Estado de Mato Grosso é uma região de grande destaque na produção de grãos para o país, a compreensão de campos regionalizados da precipitação pode ser uma ferramenta de auxílio aos produtores rurais. Neste contexto, o presente trabalho teve por objetivo a obtenção desses campos de precipitação para a região. Para tanto, utilizou-se técnicas da geoestatística; com análise variográfica e posterior krigagem ordinária de dados mensais de 22 municípios, gerando-se mapas de campos de precipitação. Os resultados permitiram identificar os menores volumes pluviométricos na porção sudoeste da área de estudo, já a distribuição espacial dos maiores valores de chuva é bastante heterogênea, com forma descontínua e observaram-se também várias localidades com precipitação média mensal maior que $200 \mathrm{~mm}$. Os campos gerados permitem a determinação da época e, por conseguinte, da cultura a ser implantada para o aumento da produtividade e garantia da produção agrícola.
\end{abstract}

Palavras Chave: campos de precipitação, geoestatística, krigagem, produção agrícola.

\begin{abstract}
The southeastern of Mato Grosso State is a region with high profile in grain production for the country, the understanding of regionalized precipitation fields can be a tool of aid to producers. In this context, the present work aimed at getting those fields of precipitation to the region. For this, we used geostatistical techniques; with variogram analysis and ordinary kriging of monthly data for 22 cities, generating up maps of precipitation. The results showed the smallest rainfall amounts in the southwestern portion of the study area, the spatial distribution of the highest values of rain is very heterogeneous, with discontinuous and it is also observed several locations with average monthly rainfall greater than $200 \mathrm{~mm}$. The fields generated permit the determination of the time and culture to be implemented to increase productivity and guarantee agricultural production
\end{abstract}

KEY WORDS: precipitation fields, geostatistics, kriging, crop.

\section{Introdução}

No intuito de aumentar a produção de alimentos em áreas cada vez mais reduzidas, $\mathrm{o}$ setor agrícola vem implementando programas cuja meta constante é a busca por novas tecnologias conjugadas ao equilíbrio ambiental. Para isto são necessárias as integrações de dados espacializados de solo, da planta e do clima, gerando informações específicas e úteis, para cada local e cultura, visando o fomento dos produtores na tomada de decisão.

Em se tratando da relação solo/planta muitos são os trabalhos e o desenvolvimento de pesquisas para suprir as necessidades dos mesmos, com práticas agrícolas de alta tecnologia e uso de vegetais mais apropriados e geneticamente melhorados (LARCHER, 2000; LACERDA, 2007). Já em relação ao clima, as alterações possíveis ao homem são restritas em tipo e escala, sendo exemplos: eventos de indução de precipitação ou mesmo mudanças microclimáticas consequentes de desflorestamentos (Mota, 1983). Entretanto, é possível ajustar as práticas agrícolas aos eventos de tempo e clima.

A geoestatística calcula estimativas dentro de um contexto regido por um fenômeno natural com distribuição no espaço e, desse modo, supõe que os valores das variáveis, consideradas como regionalizadas, sejam espacialmente 
correlacionados. O termo geoestatística é consagrado como um tópico especial da estatística aplicada, que trata de problemas referentes a variáveis regionalizadas, as quais têm um comportamento espacial mostrando características intermediárias entre as variáveis verdadeiramente aleatórias e aquelas totalmente determinísticas (Landim \& Sturaro, 2002).

$$
\text { Apresentam uma aparente }
$$

continuidade no espaço, sendo representadas por funções numéricas ordinárias que assumem um valor definido a cada ponto no espaço e, matematicamente, descrevem um fenômeno natural. A continuidade geográfica atribuída se manifesta pela propriedade que a variável tem de apresentar valores muito próximos em dois pontos vizinhos e progressivamente mais diferentes à medida que os pontos vão ficando mais distantes. Além dessa propriedade a variável regionalizada pode apresentar os seguintes atributos: localização, anisotropia e transição (Landim, 2003). Devido a essa característica, sua aplicação em estimativas e/ou simulações de variáveis em locais não amostrados, tem apresentado resultados promissores (Landim \& Sturaro, 2002).

O Mato Grosso é uma das regiões produtoras de grãos, com destaque para a o sudeste do Estado, tem sua economia predominantemente agrícola e segundo Cunha (2006), caracteriza-se não apenas pelo domínio de grandes latifúndios, mas também por uma produção primária baseada na monocultura e/ou pecuária extensiva. Nessa área é dominante o ambiente do Cerrado brasileiro, com período de seca de mais de seis meses (IBGE, 2012), sendo a precipitação a variável climática que mais influencia a produção.
Os dados históricos de precipitação em nosso país não possuem boa resolução temporal e espacial, apresentam problemas em seus registros como falhas na série e mesmo na coleta dos dados, além do distanciamento dos pluviômetros (OLIVEIRA, 2008). A quantidade de estações meteorológicas, principalmente em algumas regiões como Norte e CentroOeste também é pequena, o Estado de Mato Grosso não foge a esse cenário.

Porém, a precipitação pode ser interpretada como um fenômeno regional e apesar de variável, pode-se obter um determinado padrão espacial da mesma.

O presente trabalho teve por objetivo a construção de campos de precipitação para a região sudeste do estado de Mato Grosso, utilizando técnicas de geoestatística que levam em consideração as características espaciais de autocorrelação de variáveis regionalizadas e, consequentemente, a geração de mapas do potencial hídrico mensal para subsídio dos produtores rurais.

\section{Área de Estudo}

O Estado de Mato Grosso ocupa uma área total de $903.357,908 \mathrm{~km}^{2}$, acolhe em seu território porções de três importantes biomas brasileiros, a Amazônia, o Cerrado e o Pantanal. A região do estudo corresponde ao sudeste do Estado, tem sua economia predominantemente agrícola, com a produção primária baseada na monocultura e/ou pecuária extensiva (Cunha, 2006). É composta, segundo o IBGE, por quatro microrregiões: Rondonópolis, Alto Araguaia, Primavera do Leste e Tesouro, totalizando 22 municípios, numa área total de 70.394,355 $\mathrm{km} 2 \quad(7,79 \%$ do território do Estado) (Figura1). 
Figura 1: Microrregiões brasileiras com destaque para o Mato Grosso (azul) e a área do estudo (vermelho).

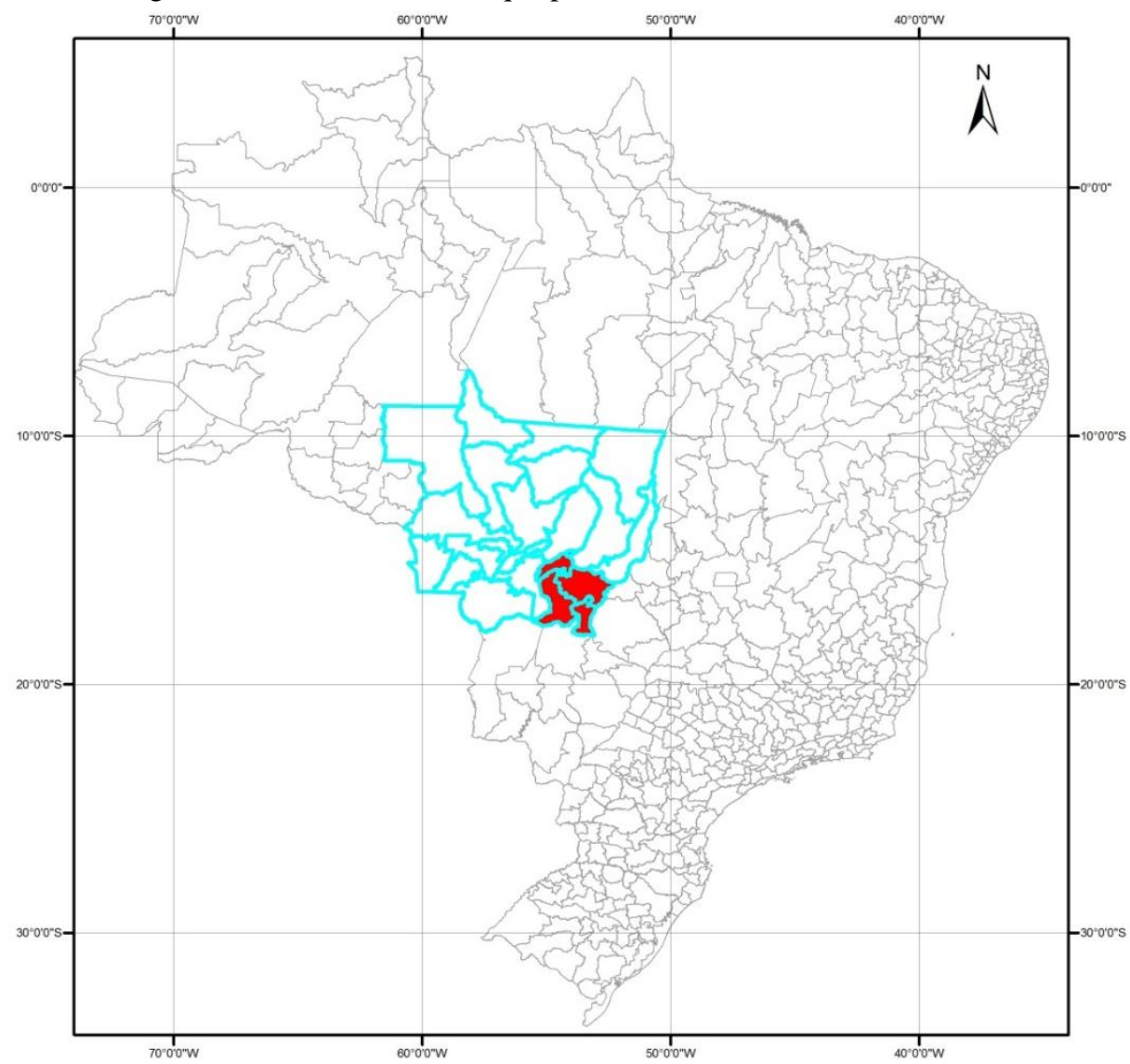

A região do estudo está sob domínio do Cerrado, fisionomia típica e característica, restrita a áreas areníticas lixiviadas com solos profundos, ocorrendo em um clima tropical eminentemente estacional com até 6 meses secos (IBGE, 2012).

\section{Material e Métodos}

Para a obtenção dos dados de precipitação da região de estudo, utilizouse as comunicações diárias de chuva para o Brasil disponíveis em FTP no endereço eletrônico: $\mathrm{ftp}: / / \mathrm{ftp}$. cpc.ncep.noaa.gov/precip/wd52ws/, com as seguintes características:

1. Origem dos dados: Centro de Missão de Coleta de Dados/Instituto Nacional de Pesquisas Espaciais CMCD/INPE, Instituto Nacional de Meteorologia - INMET, Fundação Cearense de Meteorologia e Recursos Hídricos / Ceará - FUNCEME/CE, Laboratório de Meteorologia, Recursos
Hídricos e Sensoriamento Remoto da Paraíba - LMRS/PB, Empresa de Pesquisa Agropecuária do Rio Grande do Norte EMPARN/RN, Departamento de Meteorologia e Recursos Hídricos de Pernambuco DMRH/PE, Departamento de Hidrometeorologia do Piauí DHME/PI, Companhia de Desenvolvimento Industrial e de Recursos Minerais de Sergipe CEPES/SE, Núcleo de Meteorologia e Recursos Hídricos de Alagoas NMRH/AL, Superintendência de Recursos Hídricos da Bahia SRH/BA, Companhia Energética de Minas Gerais CEMIG-SIMGE/MG, Secretaria de Estado da Agricultura do Espírito Santo SEAG/ES, Sistema Meteorológico do Paraná SIMEPAR/PR, Centro Integrado de Meteorologia e Recursos Hídricos de Santa Catarina CLIMERH/SC;

2. Definição: 1.0 grau x 1.0 grau no Sistema de Coordenada Geográfica (lat/lon); 
3. Domínio espacial: $80 \mathrm{~W}-30 \mathrm{~W}$; $40 \mathrm{~S}-10 \mathrm{~N} 4$ e domínio temporal: Janeiro (1) de 1982 a dezembro (31) de 1999.

Os dados diários de precipitação para foram extraídos e acumulados para períodos de dez dias, evitando aumentar sobremaneira o número de registros. Utilizaram-se as coordenadas (lat/lon) das 22 localidades de interesse, para a extração dos valores de chuva. Devido à resolução espacial dos dados (1 grau) houve sobreposição de algumas localidades, resultando na extração de 8 campos válidos.

Fez-se a análise exploratória para estes campos da variável precipitação, sendo obtida para cada mês do ano, as estatísticas: média acumulada mensal, desvio padrão e coeficiente de variação. Verificou-se a variação anual da chuva para cada localidade, identificando os meses mais chuvosos e o relacionamento das amostras. Este relacionamento foi verificado através de análise de agrupamento (Cluster), sendo a medida de similaridade utilizada a distância euclidiana, pelo método hierárquico de Ward, procedimento comum indicado para dados de precipitação (Reis et al., 2005).

Neste método, dado um conjunto de $n$ indivíduos para os quais existe informação sobre a forma de $p$ variáveis, o método de análise de clusters procede ao agrupamento dos indivíduos em função da informação existente, de tal modo que os indivíduos pertencentes a um mesmo grupo sejam tão semelhantes quanto possível e sempre mais semelhantes aos elementos do mesmo grupo do que a elementos de restantes grupos (Reis, 2001). Quando uma determinada amostra é tomada como um ponto no espaço das variáveis é possível calcular a distância deste ponto a todos os outros pontos, constituindo-se assim uma matriz que descreve a proximidade entre todas as amostras estudadas (Johnson \& Wichern, 1998).
Para os meses mais chuvosos foi feita a análise variográfica, técnica que permite a estimativa por médias móveis, de valores de variáveis distribuídos no espaço a partir de valores adjacentes, enquanto considerados como interdependentes por uma função denominada variograma. Como no cálculo dessa função o somatório de diferenças ao quadrado é dividido por 2 $\mathrm{x}$ número de pares de valores, o termo correto seria semivariograma (Landim, 2000; Druck et al., 2004). O modelo para a representação do semivariograma é dado pela expressão (1):

$$
\gamma(\mathrm{h})=\frac{1}{2 \mathrm{~N}(\mathrm{~h})} \sum_{\mathrm{i}=1}^{\mathrm{N}(\mathrm{h})}\left[\mathrm{z}\left(\mathrm{x}_{\mathrm{i}}\right)-\mathrm{z}\left(\mathrm{x}_{\mathrm{i}}+\mathrm{h}\right)\right]^{2}
$$

Em que: $\gamma(\mathrm{h})$ : valor do semivariograma estimado para a distância $(\mathrm{h}), \mathrm{z}\left(\mathrm{x}_{\mathrm{i}}\right)$ e $\mathrm{z}\left(\mathrm{x}_{\mathrm{i}}+\mathrm{h}\right)$ : valores medidos das variáveis nos locais correspondentes e $\mathrm{N}(\mathrm{h})$ : número de pares de valores medidos.

Os variogramas expressam o comportamento espacial da variável contínua mostrando sua zona de influência, seus aspectos anisotrópicos, e a presença de anomalias provocadas por erros de amostragem ou por componentes aleatórios (Landim, 2000).

E finalmente, com base nos variogramas, ajustaram-se modelos para cada mês e efetuou-se a krigagem com tendência obtendo os mapas de campos mensais da chuva espacializados, representando a disponibilidade hídrica da região Sudeste do Estado de Mato Grosso.

Se uma variável regionalizada $v(i)$ for coletada em diversos pontos $i$, $o$ valor de cada ponto estará relacionado com valores obtidos a partir de pontos situados a uma certa distância $h$ e a influência será tanto maior quanto menor for a distância entre os pontos (Landim \& Sturaro, 2002). 
Citação: Oliveira J. R. T., Oliveira L. M. T., Distribuição Espacial da Precipitação para a Região Sudeste do Estado De Mato Grosso. E\&S - Engineering and Science, (2014), 2:1.

\section{Resultados e Discussão}

O agrupamento dos oito campos válidos, contendo as 22 localidades, gerou o dendrograma apresentado na Figura 2.

Figura 2. Dendrograma dos oito campos pela variável precipitação.

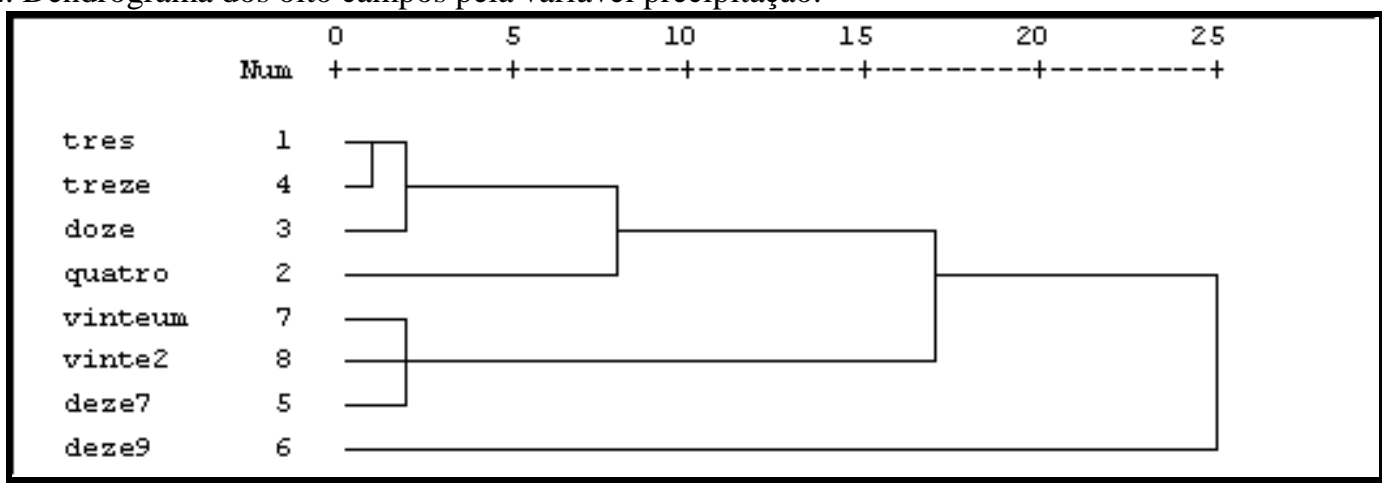

A análise do dendrograma sugere a formação de quatro grupos a partir dos 22 municípios, que foram denominados de
MR1, MR2, MR3 e MR4, e são apresentados na Tabela 1 .

Tabela 1. Localidades agrupadas por região, em função da similaridade da pluviosidade.

\begin{tabular}{llllc}
\hline \multicolumn{1}{c}{ Localidade } & Altitude & Cluster & Região & $\begin{array}{c}\text { Altitude } \\
\text { média }\end{array}$ \\
Alto Araguaia & 692 & 1 & MR3=Rondonópolis & 417 \\
Alto Taquari & 851 & 1 & & \\
Juscimeira & 251 & 1 & & \\
Pedra Preta & 248 & 1 & & \\
Rondonópolis & 227 & 1 & & 736 \\
São José do Povo & 281 & 1 & & \\
Itiquira & 522 & 1 & & \\
São Pedro da Cipa & 264 & 1 & & \\
Campo Verde & 736 & 2 & MR2=Campo Verde & \\
Alto Garças & 754 & 3 & MR4=Tesouro & \\
Araguainha & 462 & 3 & & \\
General Carneiro & 343 & 3 & & \\
Guiratinga & 510 & 3 & & \\
Pontal do Araguaia & 300 & 3 & & \\
Ponte Branca & 424 & 3 & & \\
Ribeirãozinho & 477 & 3 & & \\
Tesouro & 410 & 3 & & \\
Torixoréu & 335 & 3 & & \\
Jaciara & 367 & 4 & MR1=Primavera do \\
Dom Aquino & 283 & 4 & Leste & \\
Poxoréo & 360 & 4 & & \\
Primavera do Leste & 500 & 4 & & \\
\hline & & & & \\
\hline
\end{tabular}

As quatro microrregiões resultantes do agrupamento dos valores de precipitação podem ser visualizadas na Figura 3. 
Citação: Oliveira J. R. T., Oliveira L. M. T., Distribuição Espacial da Precipitação para a Região Sudeste do Estado De Mato Grosso. E\&S - Engineering and Science, (2014), 2:1.

Figura 3. Agrupamento das microrregiões pela precipitação, MR1= Primavera do Leste, MR2= Campo Verde, MR3= Rondonópolis e MR4= Tesouro.

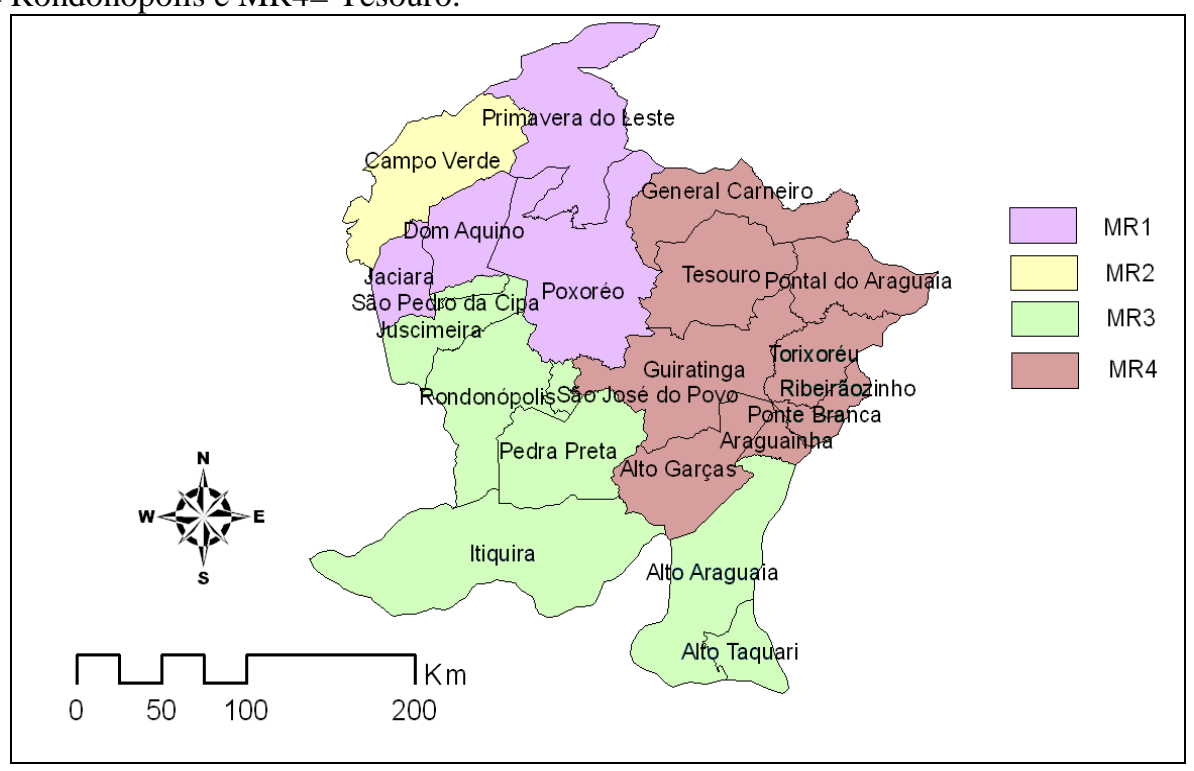

Pela análise das estatísticas (Tabela 2), observou-se que a distribuição das chuvas no decorrer do ano possui duas estações bem definidas, uma seca e outra chuvosa, sendo a estação chuvosa compreendida entre os meses de outubro a abril. A região de Primavera do Leste apresenta os maiores coeficientes de variação, indicando ser uma região com maiores amplitudes de variação e portanto, relativamente, mais dependente da precipitação. A região de Tesouro apresentou as maiores médias pluviométricas na estação chuvosa, em relação aos outros três grupos a região parece não sofrer déficit pluviométrico e sugere boas condições para a agricultura nesse período.

Tabela 2. Estatísticas do acumulado médio mensal de precipitação (mm) das quatro microrregiões agrupadas, no decorrer do ano.

\begin{tabular}{|c|c|c|c|c|c|}
\hline & & \multicolumn{4}{|c|}{ Região } \\
\hline Mês & Estatística & $\begin{array}{l}\text { Rondonópolis } \\
\text { MR3 }\end{array}$ & $\begin{array}{l}\text { Campo } \\
\text { Verde } \\
\text { MR2 }\end{array}$ & $\begin{array}{l}\text { Tesouro } \\
\text { MR4 }\end{array}$ & $\begin{array}{l}\text { Primavera } \\
\text { do Leste } \\
\text { MR1 }\end{array}$ \\
\hline \multirow[t]{3}{*}{ janeiro } & média acumulada & 244,17 & 243,57 & 277,46 & 263,22 \\
\hline & desvio padrão & 60,35 & 69,48 & 76,04 & 89,92 \\
\hline & $\mathrm{cv} \%$ & $25 \%$ & $29 \%$ & $27 \%$ & $34 \%$ \\
\hline \multirow[t]{3}{*}{ fevereiro } & média acumulada & 210,56 & 211,07 & 229,04 & 209,07 \\
\hline & desvio padrão & 47,56 & 60,64 & 66,8 & 58,88 \\
\hline & $\mathrm{cv} \%$ & $23 \%$ & $29 \%$ & $29 \%$ & $28 \%$ \\
\hline \multirow[t]{3}{*}{ março } & média acumulada & 197,46 & 207,65 & 231,9 & 226,92 \\
\hline & desvio padrão & 52,25 & 56,87 & 54,32 & 94,1 \\
\hline & $\mathrm{cv} \%$ & $26 \%$ & $27 \%$ & $23 \%$ & $41 \%$ \\
\hline \multirow[t]{3}{*}{ abril } & média acumulada & 105,16 & 105,36 & 107,98 & 120,62 \\
\hline & desvio padrão & 24,07 & 29,7 & 34,01 & 41,51 \\
\hline & $\mathrm{cv} \%$ & $23 \%$ & $28 \%$ & $31 \%$ & $34 \%$ \\
\hline \multirow[t]{3}{*}{ maio } & média acumulada & 56,56 & 48,97 & 46,71 & 42,58 \\
\hline & desvio padrão & 30,27 & 30,85 & 23,18 & 31,58 \\
\hline & $\mathrm{cv} \%$ & $54 \%$ & $63 \%$ & $50 \%$ & $74 \%$ \\
\hline junho & média acumulada & 26,22 & 20,76 & 23,53 & 16,49 \\
\hline
\end{tabular}


Citação: Oliveira J. R. T., Oliveira L. M. T., Distribuição Espacial da Precipitação para a Região Sudeste do Estado De Mato Grosso. E\&S - Engineering and Science, (2014), 2:1.

Continua ...Tabela 2. Estatísticas do acumulado médio mensal de precipitação ( $\mathrm{mm}$ ) das quatro microrregiões agrupadas, no decorrer do ano.

\begin{tabular}{|c|c|c|c|c|c|}
\hline & desvio padrão & 32,66 & 18,65 & 37,04 & 19,24 \\
\hline & $\mathrm{cv} \%$ & $125 \%$ & $90 \%$ & $157 \%$ & $117 \%$ \\
\hline \multirow[t]{3}{*}{ julho } & média acumulada & 12,08 & 10,07 & 6,98 & 7,19 \\
\hline & desvio padrão & 14,52 & 14,21 & 8,13 & 11,91 \\
\hline & $\mathrm{cv} \%$ & $120 \%$ & $141 \%$ & $117 \%$ & $166 \%$ \\
\hline \multirow[t]{3}{*}{ agosto } & média acumulada & 23,28 & 20,12 & 20,38 & 17,09 \\
\hline & desvio padrão & 27,95 & 26,21 & 25,69 & 26,14 \\
\hline & $\mathrm{cv} \%$ & $120 \%$ & $130 \%$ & $126 \%$ & $153 \%$ \\
\hline \multirow[t]{3}{*}{ setembro } & média acumulada & 61,88 & 67,59 & 67,34 & 67,28 \\
\hline & desvio padrão & 42,33 & 45,95 & 38,3 & 57,99 \\
\hline & $\mathrm{cv} \%$ & $68 \%$ & $68 \%$ & $57 \%$ & $86 \%$ \\
\hline \multirow[t]{3}{*}{ outubro } & média acumulada & 117,2 & 122,45 & 122,59 & 149,41 \\
\hline & desvio padrão & 29,78 & 29,96 & 22,95 & 55,45 \\
\hline & $\mathrm{cv} \%$ & $25 \%$ & $24 \%$ & $19 \%$ & $37 \%$ \\
\hline \multirow[t]{3}{*}{ novembro } & média acumulada & 171,4 & 159,08 & 190,03 & 180,31 \\
\hline & desvio padrão & 54,31 & 47,15 & 51,77 & 72,34 \\
\hline & $\mathrm{cv} \%$ & $32 \%$ & $30 \%$ & $27 \%$ & $40 \%$ \\
\hline \multirow[t]{3}{*}{ dezembro } & média acumulada & 219,32 & 220,67 & 269,29 & 254,34 \\
\hline & desvio padrão & 62,07 & 74,92 & 72,95 & 129,45 \\
\hline & $\mathrm{cv} \%$ & $28 \%$ & $34 \%$ & $27 \%$ & $51 \%$ \\
\hline
\end{tabular}

A análise variográfica indicou a presença de anisotropia em todos os meses estudados, ou seja, a variabilidade não é a mesma em todas as direções. O mapa variográfico para o mês de outubro é um exemplo disso e pode ser visto na Figura 4. A partir desses resultados foram gerados variogramas nas quatro direções: $\mathrm{L}-\mathrm{O}, \mathrm{N}$ -
S, NE-SO e NO-SE, todos com abertura angular de $45^{\circ}$. Os variogramas mostraram anisotropia zonal, ou seja, ao serem consideradas diferentes direções a amplitude permanece constante e o patamar varia, este comportamento está associado ao zoneamento espacial da variável.

Figura 4. Mapa de Variogramas para o mês de outubro.

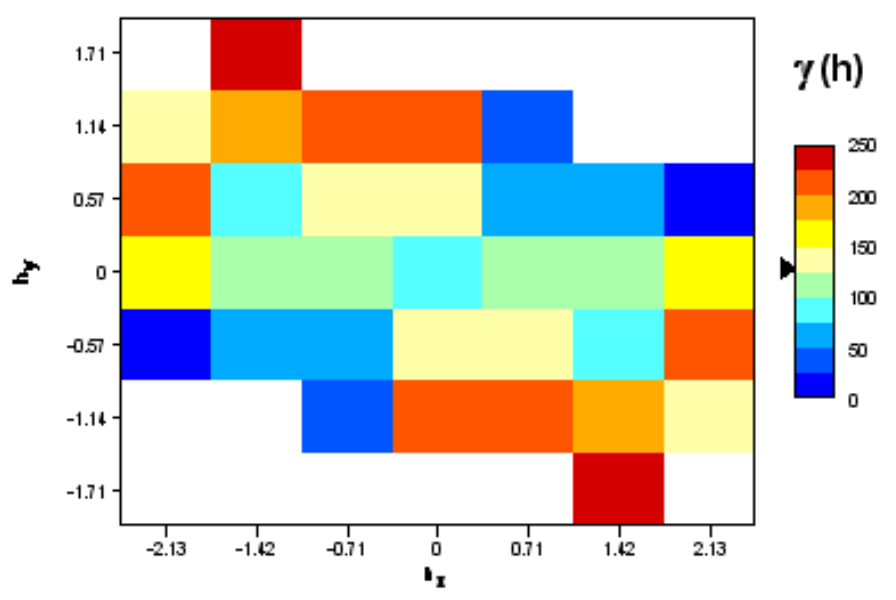

Nas Figuras de 5 a 9 são mostradas a

distribuição da precipitação na região 
Citação: Oliveira J. R. T., Oliveira L. M. T., Distribuição Espacial da Precipitação para a Região Sudeste do Estado De Mato Grosso. E\&S - Engineering and Science, (2014), 2:1.

Sudeste do Estado, que foram gerados estação seca do ano. através da krigagem ordinária para a

Figura 5. Espacialização da precipitação acumulada média $(\mathrm{mm})$ para o mês de maio.

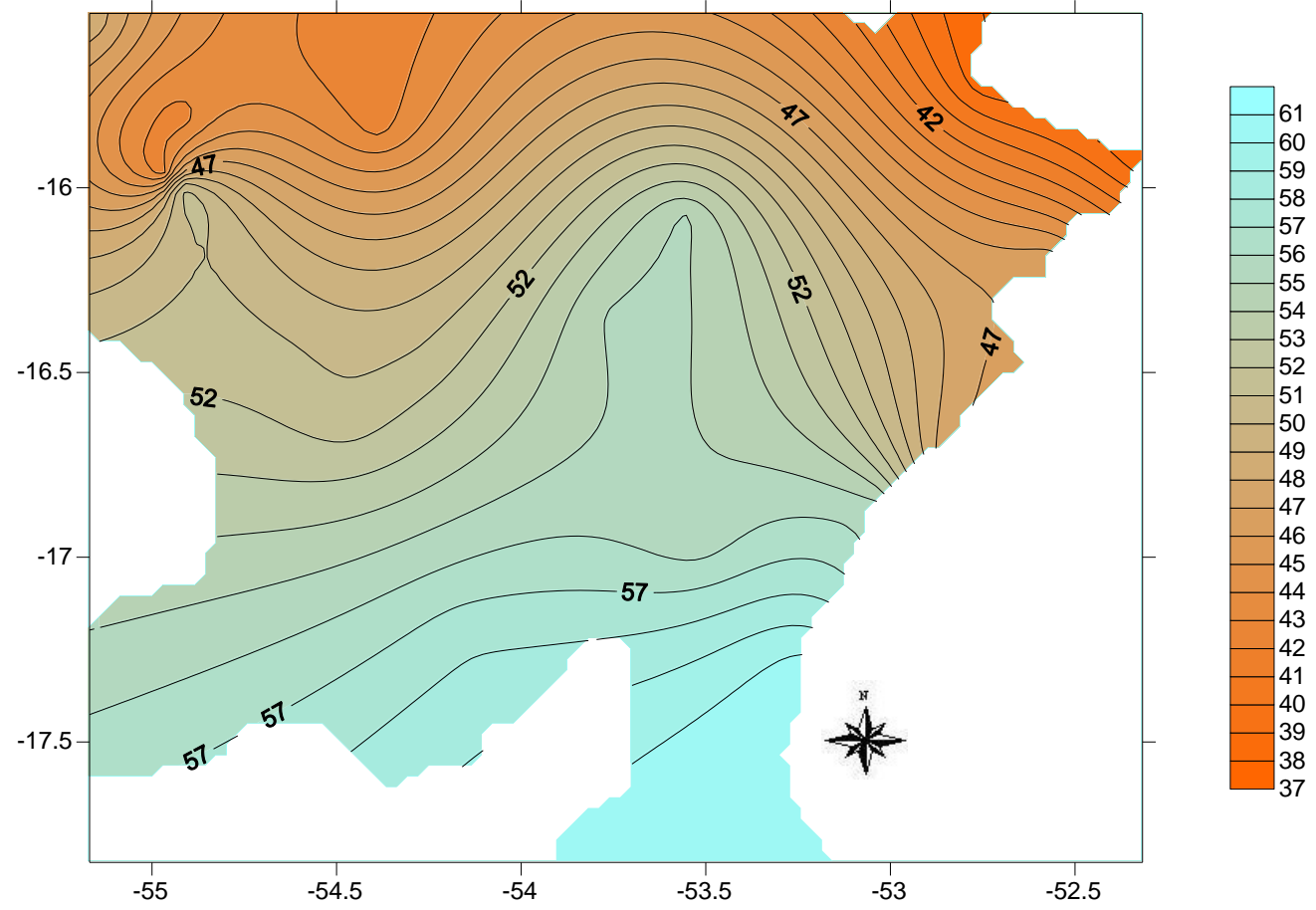

Figura 6. Espacialização da precipitação acumulada média $(\mathrm{mm})$ para o mês de junho.

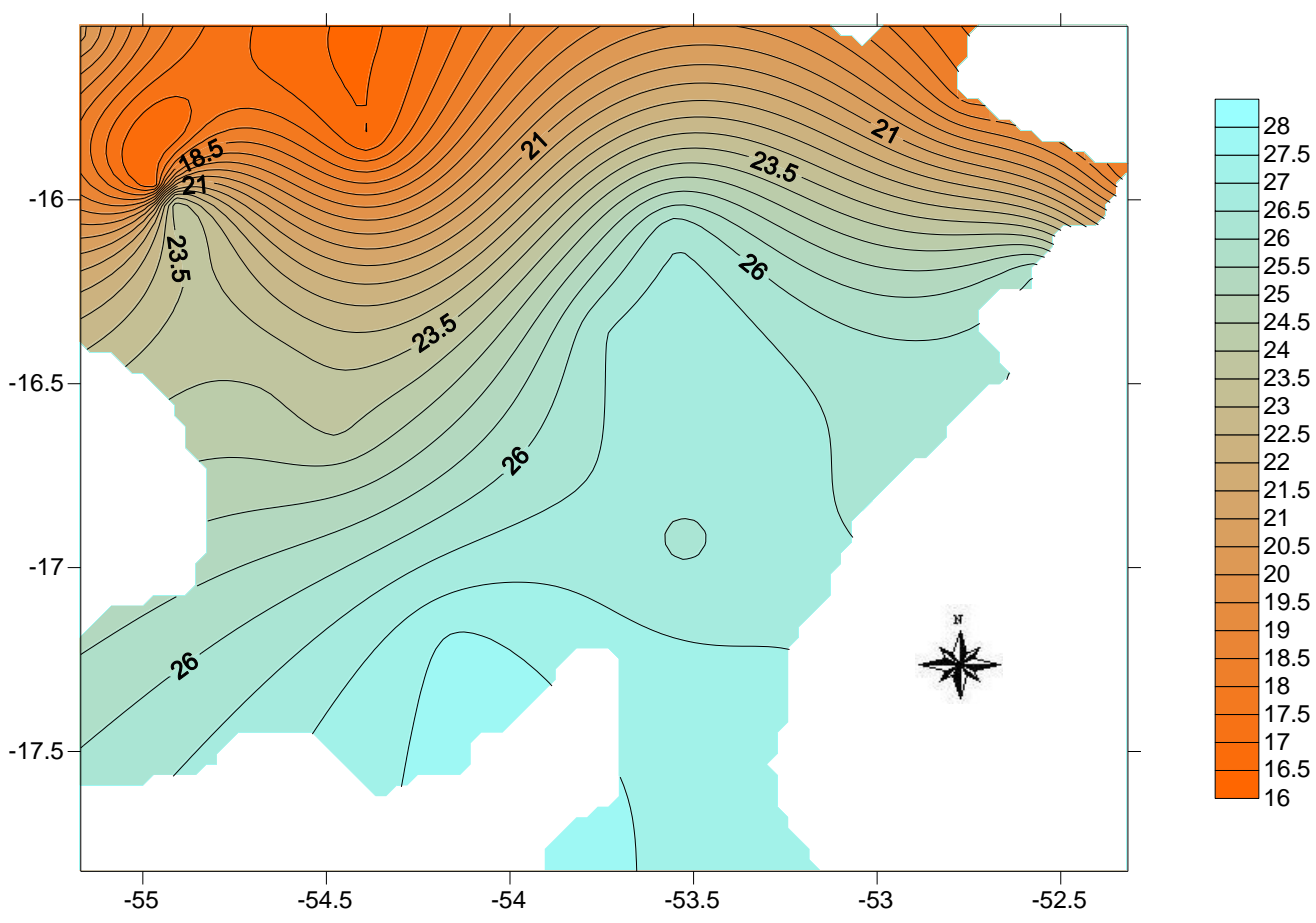


Citação: Oliveira J. R. T., Oliveira L. M. T., Distribuição Espacial da Precipitação para a Região Sudeste do Estado De Mato Grosso. E\&S - Engineering and Science, (2014), 2:1.

Figura 7. Espacialização da precipitação acumulada média (mm) para o mês de julho.

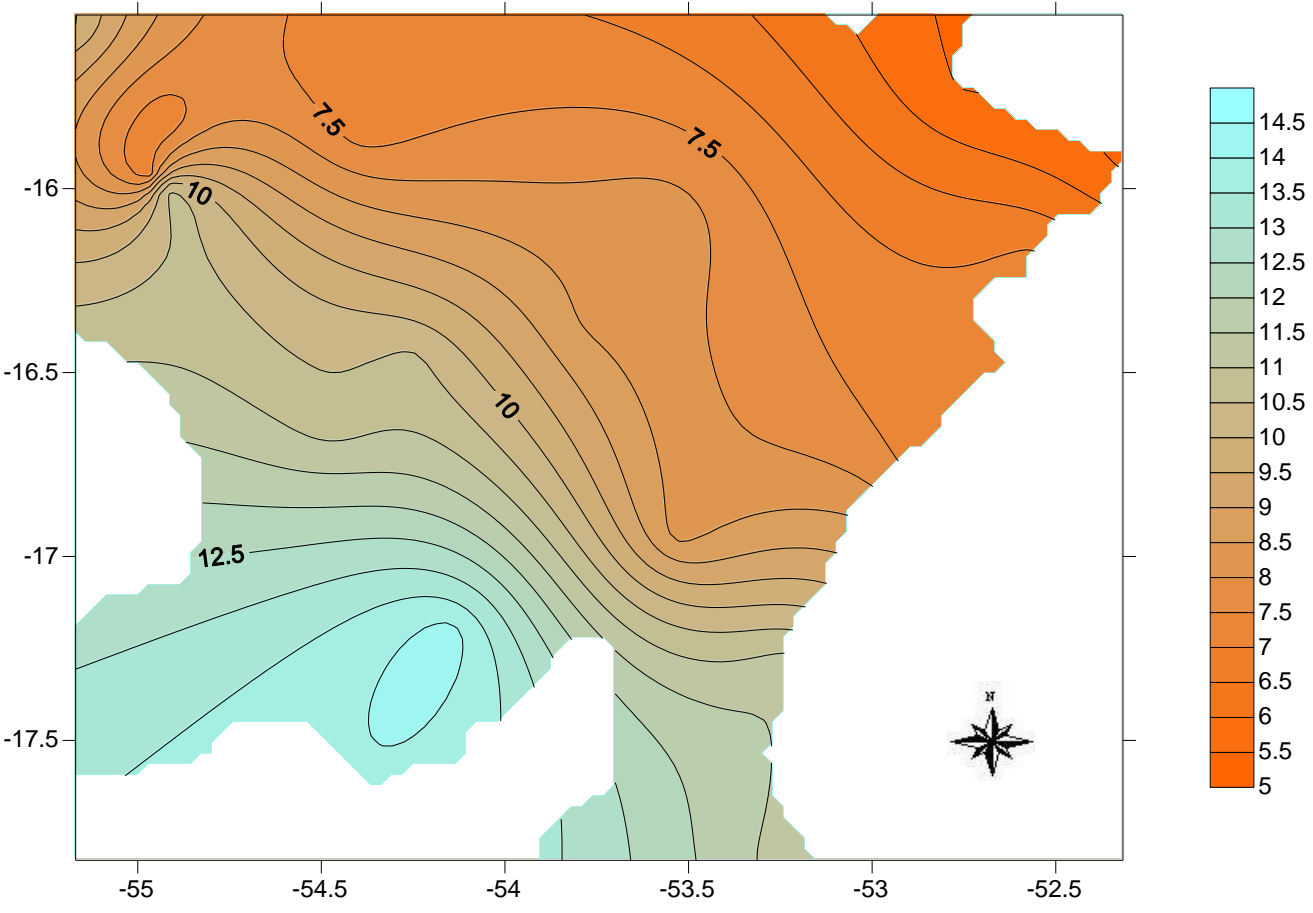

Figura 8. Espacialização da precipitação acumulada média $(\mathrm{mm})$ para o mês de agosto.

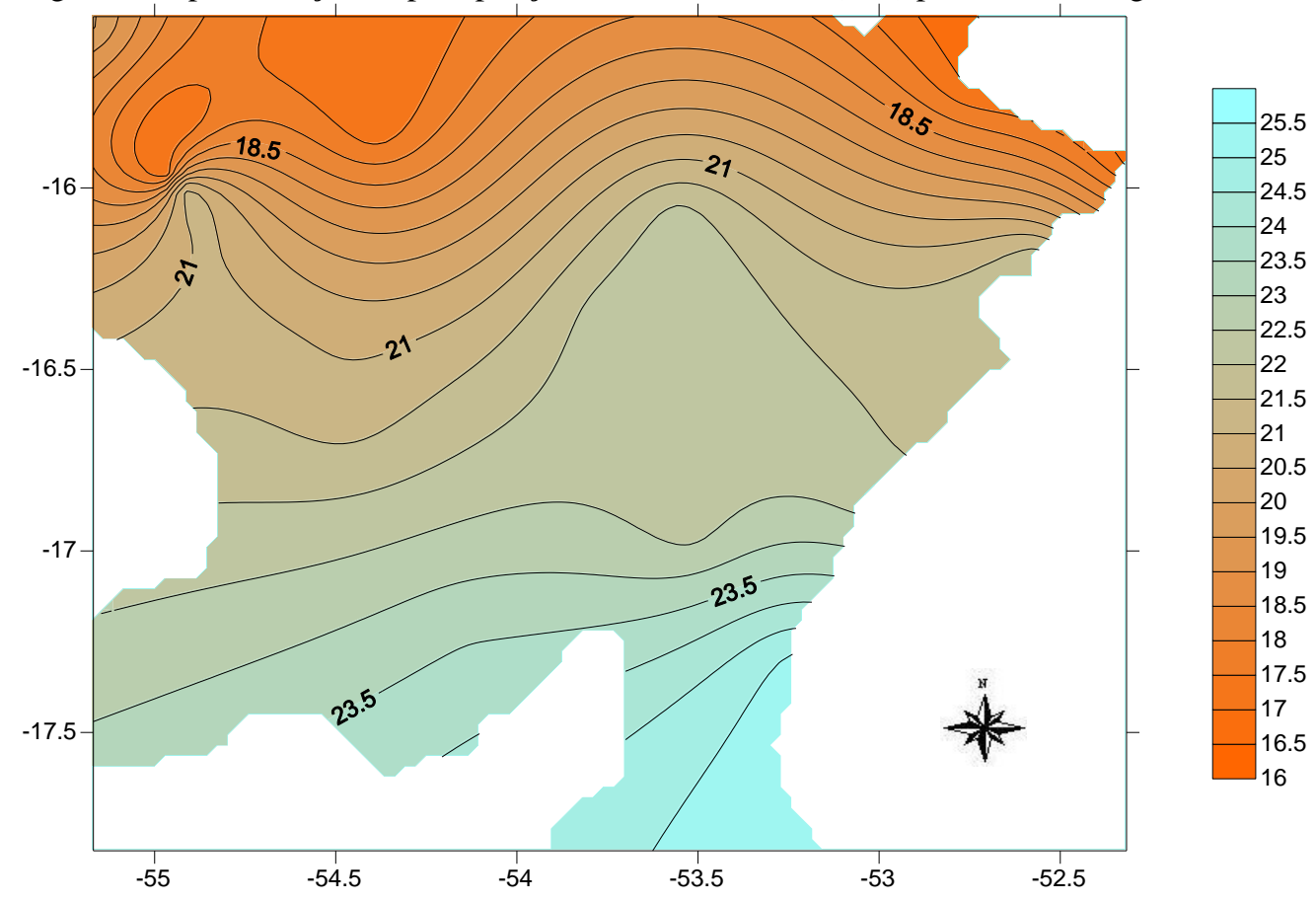


Citação: Oliveira J. R. T., Oliveira L. M. T., Distribuição Espacial da Precipitação para a Região Sudeste do Estado De Mato Grosso. E\&S - Engineering and Science, (2014), 2:1.

Figura 9. Espacialização da precipitação acumulada média (mm) para o mês de setembro.

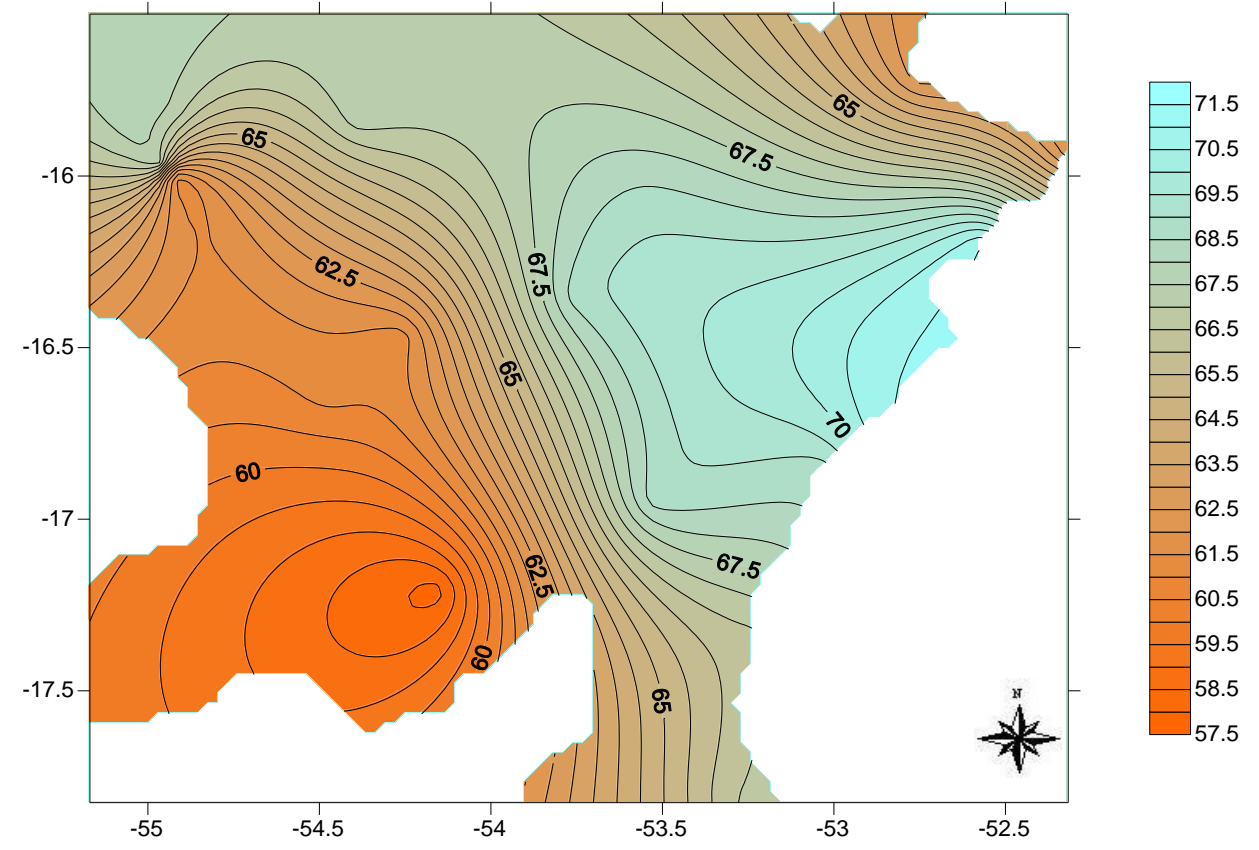

O mês de julho (Figura 7) apresenta os menores valores de precipitação, sendo considerado o pico da estação seca, as Figuras 6 e 8 apresentam o mesmo padrão de precipitação, sendo menor na porção norte e mais favorável na sul, a Figura 5 apresenta na porção sul acumulados de até $57 \mathrm{~mm}$, e a Figura 9 mantém a precipitação ao sul e apresenta uma melhora no centro da região chegando a acumulado de 67 $\mathrm{mm}$.

A MR2 é a microrregião mais seca nesses meses, apresentando maiores valores apenas em setembro. Já a MR3 apresenta os maiores valores relativos no período seco, porém em setembro é a região com menores valores de precipitação, mostrando uma melhor distribuição em relação às outras microrregiões (interessante para a produção).

As Figuras de 10 a 16 apresentam os campos de precipitação na região sudeste do estado de Mato Grosso, gerados através da krigagem ordinária para a estação úmida do ano.

Figura 10. Espacialização da precipitação acumulada média (mm) para o mês de outubro.

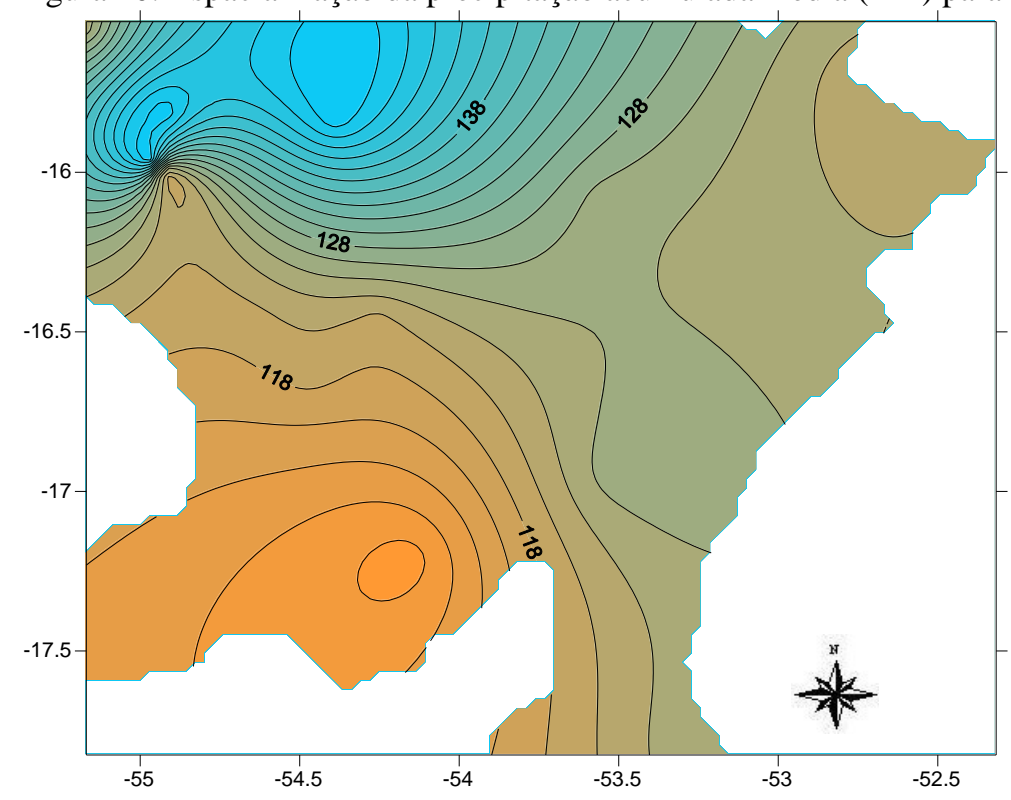


Citação: Oliveira J. R. T., Oliveira L. M. T., Distribuição Espacial da Precipitação para a Região Sudeste do Estado De Mato Grosso. E\&S - Engineering and Science, (2014), 2:1.

Figura 11. Espacialização da precipitação acumulada média (mm) para o mês de novembro.

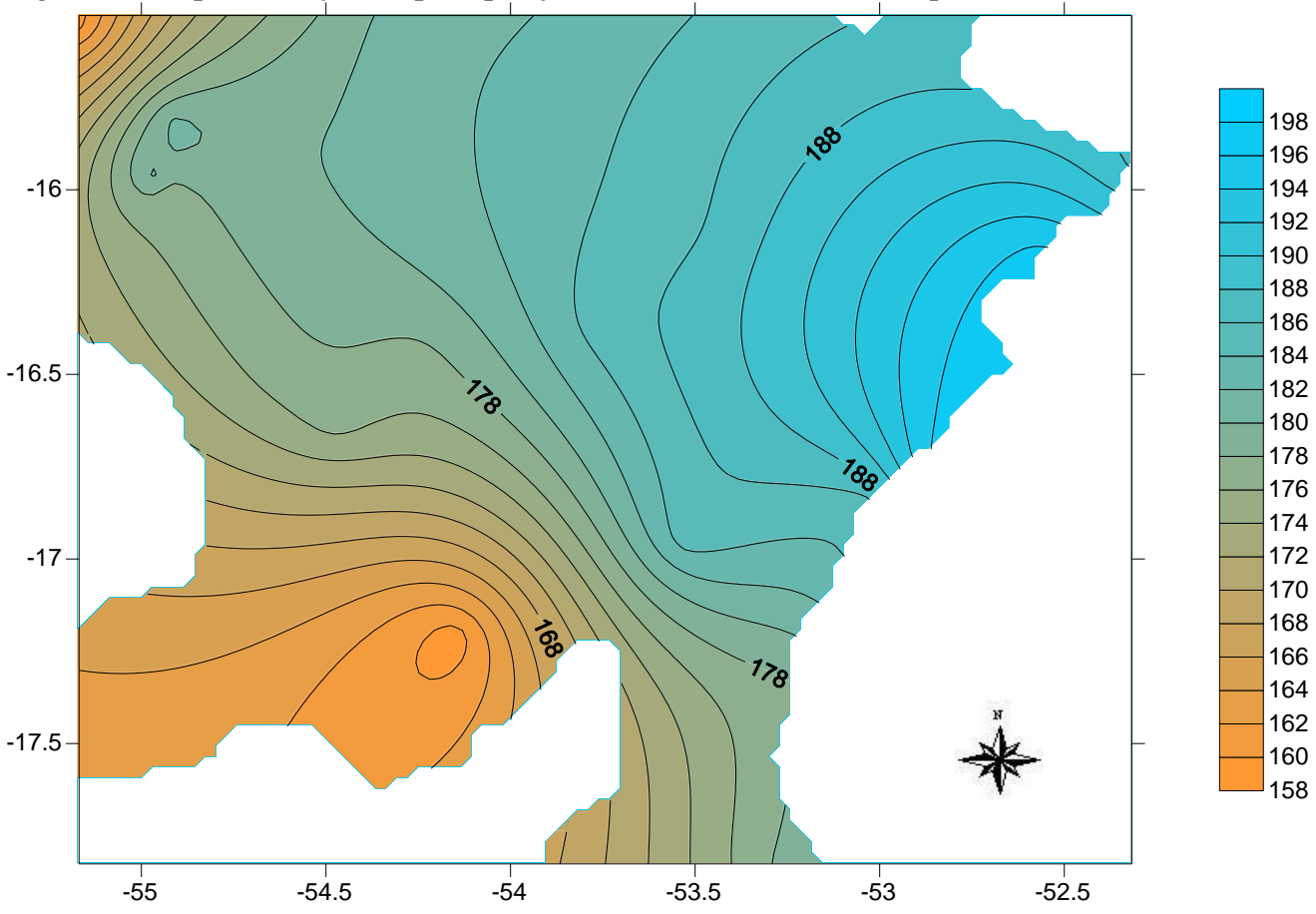

Figura 12. Espacialização da precipitação acumulada média ( $\mathrm{mm})$ para o mês de dezembro.

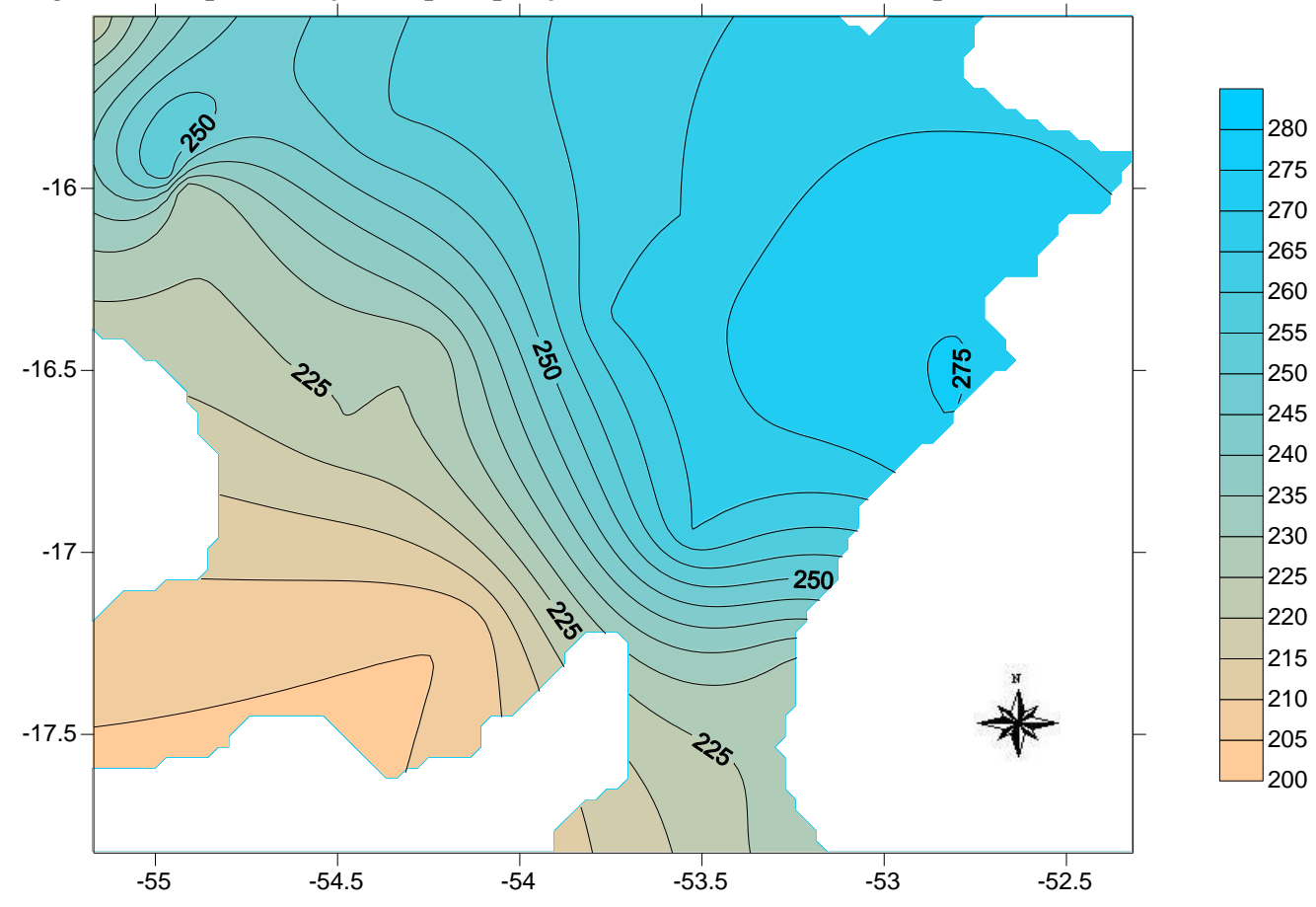


Citação: Oliveira J. R. T., Oliveira L. M. T., Distribuição Espacial da Precipitação para a Região Sudeste do Estado De Mato Grosso. E\&S - Engineering and Science, (2014), 2:1.

Figura 13. Espacialização da precipitação acumulada média $(\mathrm{mm})$ para o mês de janeiro.

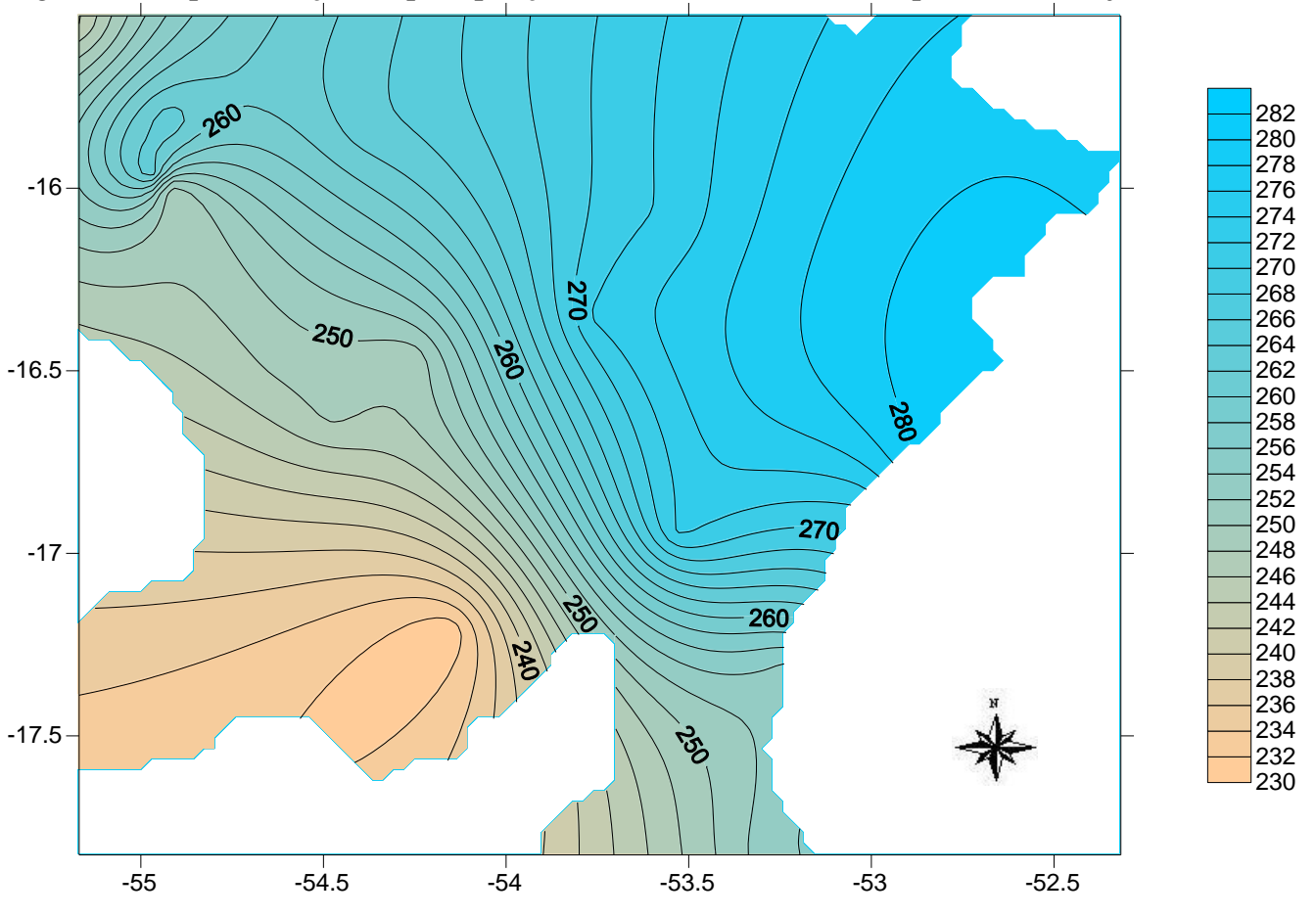

Figura 14. Espacialização da precipitação acumulada média (mm) para o mês de fevereiro.

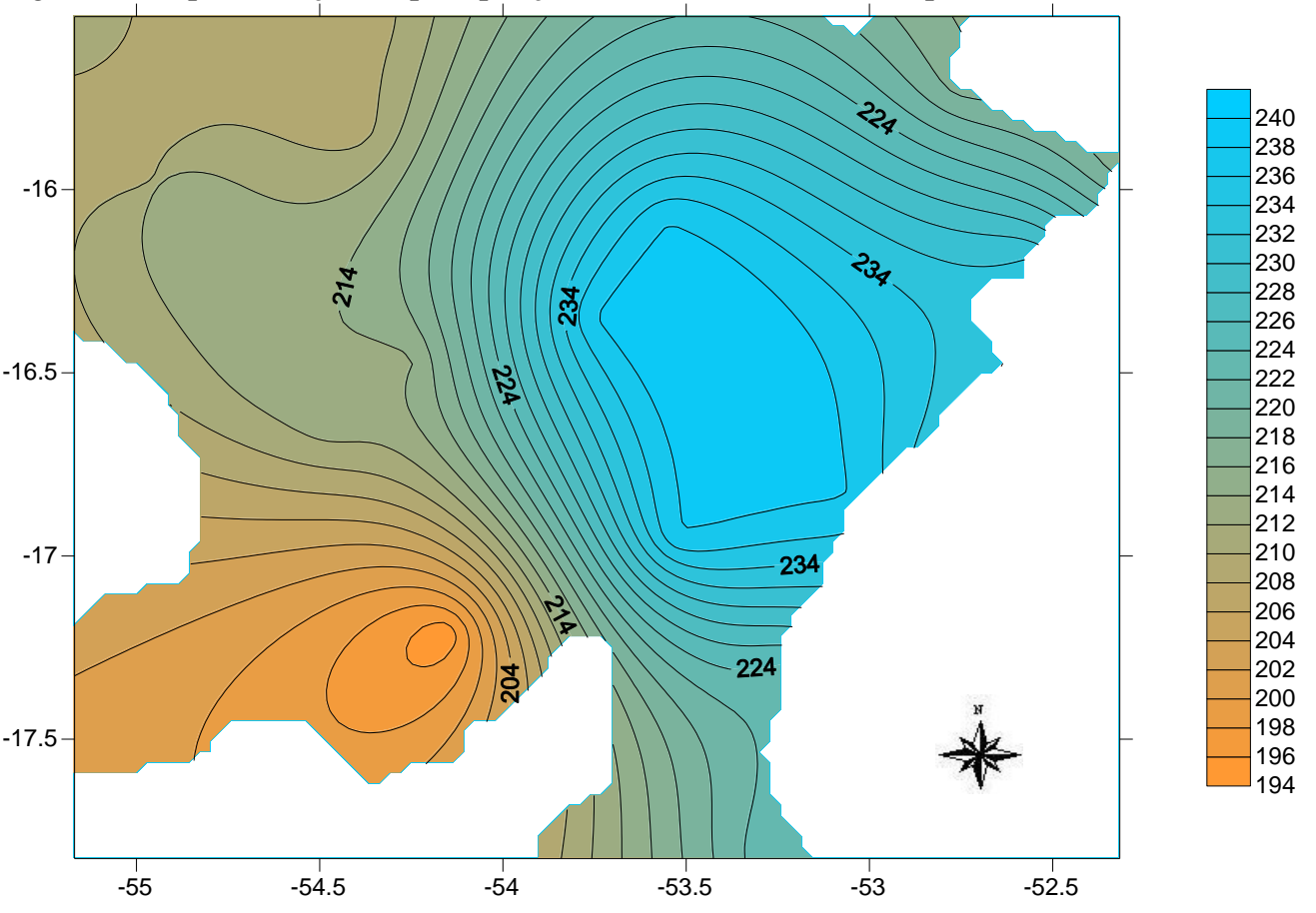


Citação: Oliveira J. R. T., Oliveira L. M. T., Distribuição Espacial da Precipitação para a Região Sudeste do Estado De Mato Grosso. E\&S - Engineering and Science, (2014), 2:1.

Figura 15. Espacialização da precipitação acumulada média $(\mathrm{mm})$ para o mês de março.

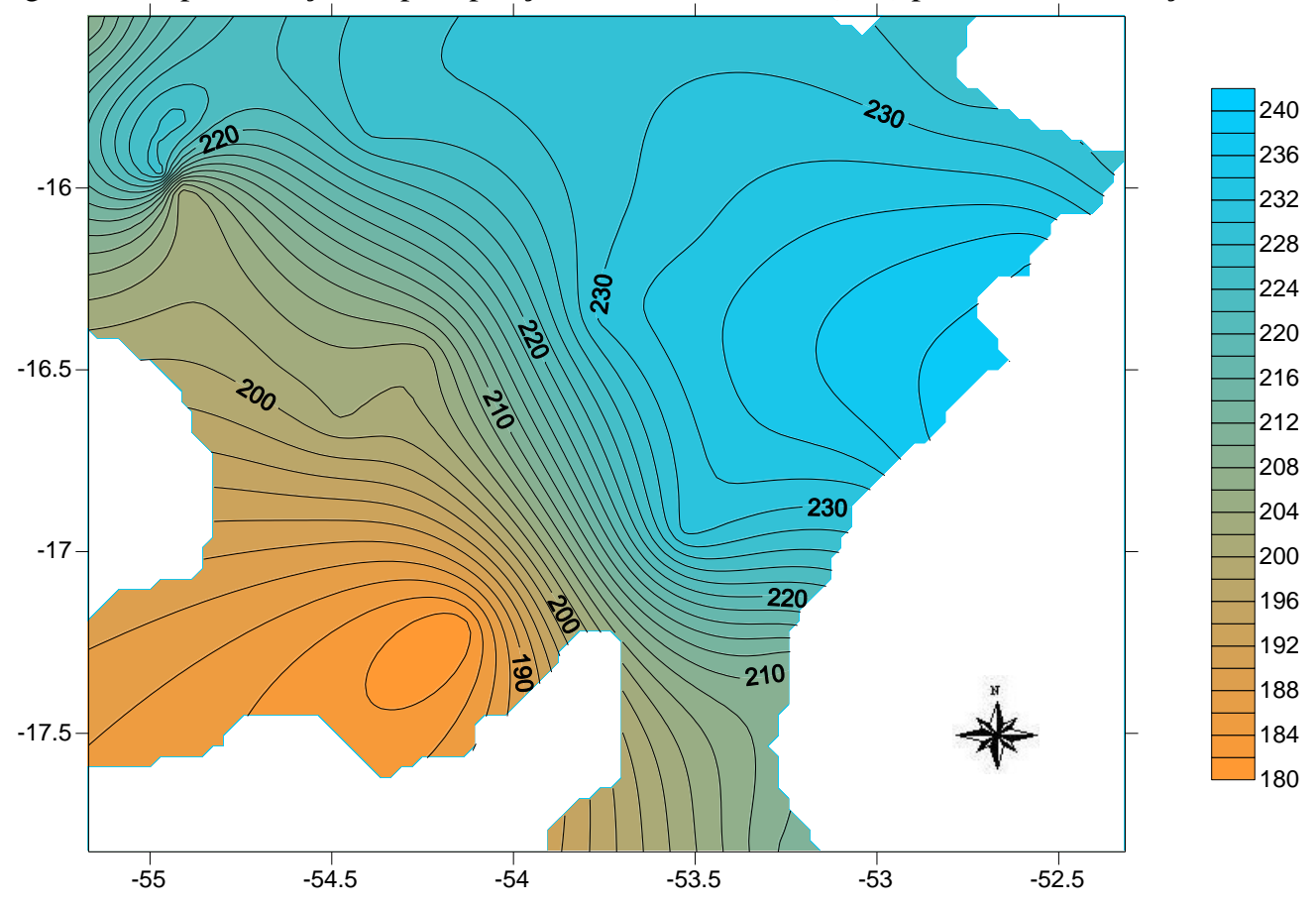

Figura 16. Espacialização da precipitação acumulada média (mm) para o mês de abril.

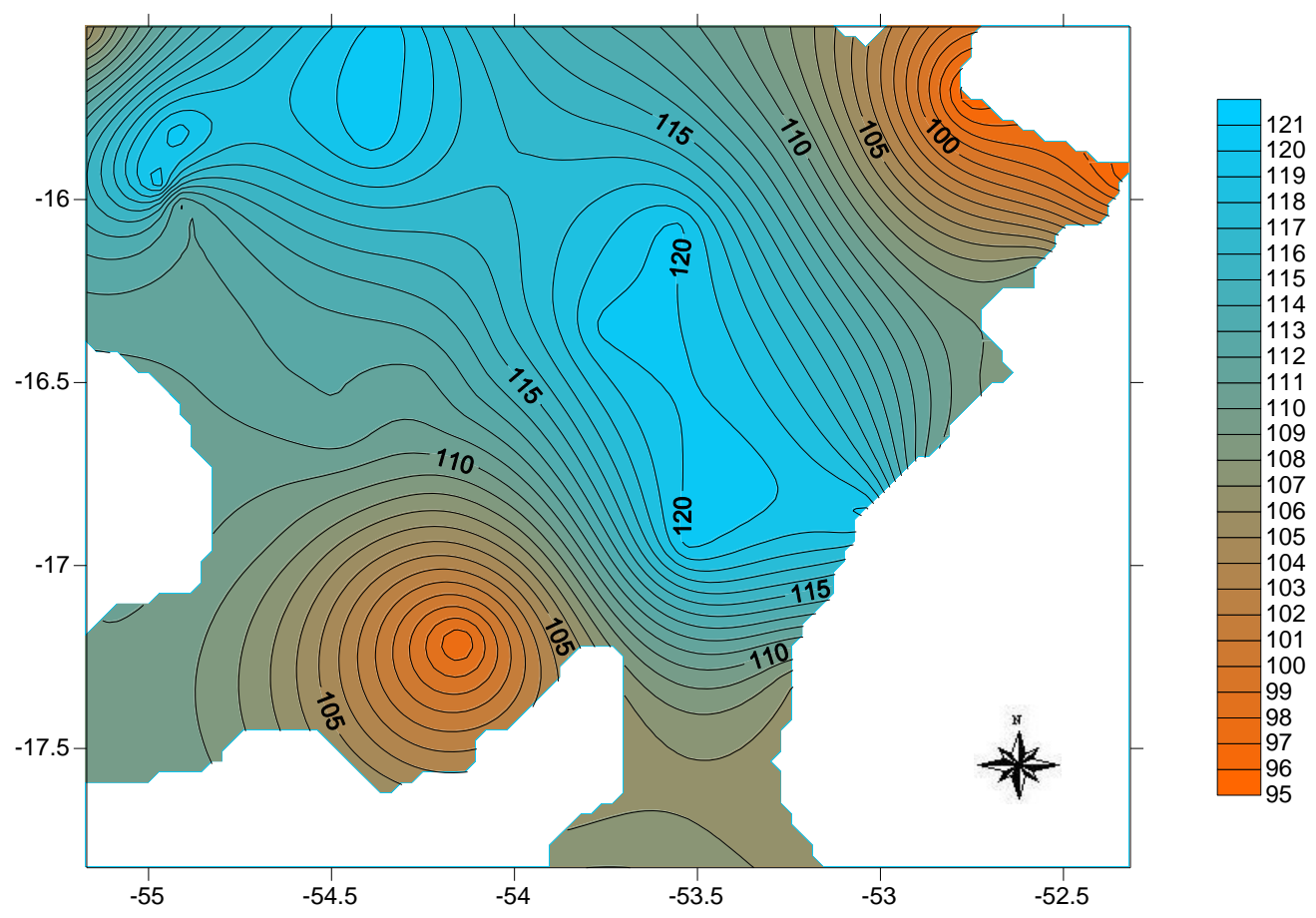

Para os meses de novembro a Janeiro (Figuras 11 a 13), a tendência da precipitação apresenta menor variabilidade de noroeste para sudeste e maior de nordeste para sudoeste. A MR4 foi a microrregião com os maiores valores 
relativos de precipitação no período úmido e a MR3 os menores.

A MR3 é a microrregião com maior equivalência entre os períodos seco e úmido. E a MR4 apresenta os valores mais extremos, mostrando-se uma região mais seca no período seco e a mais úmida no período das chuvas.

Para o mês de fevereiro a Figura 14 apresenta a menor variabilidade do MR4 para a MR3, a maior disponibilidade hídrica ocorre no centro da MR4, com pluviosidade acumulada variando de 194 $\mathrm{mm}$ a $240 \mathrm{~mm}$.

$\mathrm{Na}$ Figura 15, observa-se maior intensidade ocorrendo nas MR1 e MR4 e nas localidades de Campo Verde e Alto Araguaia estão concentrados os maiores volumes de disponibilidade hídrica para o mês de março e de abril, encerrando o período chuvoso. A Figura 16 apresenta uma menor disponibilidade hídrica na MR3 e no nordeste da MR4, com precipitações médias acumuladas que variaram de $95 \mathrm{~mm}$ a $121 \mathrm{~mm}$.

\section{Conclusões}

O presente trabalho possibilitou a obtenção de Distribuição espacial padrão da precipitação média acumulada para a região sudeste do Estado de Mato Grosso.

A resolução espacial, os dados permitiram a confirmação do período chuvoso, outubro a abril. A geoestatística pode ajudar nas análises da série de dados da rede meteorológica e também em seu planejamento.

$\mathrm{Na}$ porção Sudoeste da área de estudo foram registrados os menores valores da precipitação na estação úmida. Neste mesmo período há uma distribuição espacial bastante heterogênea dos maiores valores de chuva, com forma descontínua, apresentando várias localidades com precipitação maior que $200 \mathrm{~mm}$.
O conhecimento da distribuição espacial da precipitação média acumulada e a possibilidade de acompanhar a variabilidade no tempo e no espaço contribuem para o desenvolvimento da agricultura, possibilitando planejamento adequado da atividade.

\section{Referências}

CUNHA, J. M. P. Dinâmica migratória e o processo de ocupação do Centro-Oeste brasileiro: o caso de Mato Grosso. Revista Brasileira de Estudos de População, São Paulo, v. 23, n. 1, p. 87-107, jan./jun. 2006.

DRUCK, S. et al. (Eds.) Análise espacial de dados geográficos. Brasília, DF. EMBRAPA, 2004.

IBGE, Manual Técnico da Vegetação Brasileira, Rio de Janeiro, IBGE, Série Manuais Técnicos em Geociências, número I, 275 p., 2012

JOHNSON, R.A.; WICHERN, D.W. Applied multivariate statistical analysis. 5th ed. New Jersey: Prentice Hall, 2002. $767 \mathrm{p}$.

LACERDA, C. F., Relações solo-águaplanta em ambientes naturais e agrícolas do nordeste brasileiro. Recife, PE, UFRPE. 78p., 2007. Disponível em:<< https://portais.ufg.br/uploads/68/original_APOSTIL A_RELA_ES_SOLOS_GUA_PLANTA.pdf $>>$

LARCHER, W. Ecofisiologia Vegetal. São Carlos, riMa Artes e Textos, 2000. $531 \mathrm{p}$.

LANDIM, P. M. B. Análise estatística de dados geológicos. 2 ed. São Paulo. Fundação Editora da UNESP, 2003. 253p.

LANDIM, P. M. B., STURARO, J. R. Krigagem indicativa aplicada à elaboração de mapas probabilísticos de riscos. Rio Claro: DGA; IGCE; UNESP, Laboratório Geomatemática, 2000. 19 p. (Texto didático, 6). Disponível em: <http://www.rc.unesp.br/igce/aplicada/text odi.html>. Acesso em: 12 ago. 2006. 
LANDIM, P. M. B. Introdução aos métodos de estimação espacial para confecção de mapas. Rio Claro: DGA, IGCE, UNESP, Laboratório Geomatemática, 2000. 20 p.(Texto didático, 2) Disponível em: < http://www. rc.UNESP.br/igce/aplicada/ textodi. html>. Acesso em:16 jan. 2007.

MOTA, F. S. Meteorologia agrícola, 6 ${ }^{a}$.ed. São Paulo: Livraria Nobel,1983. $376 \mathrm{p}$.

REIS, E. Estatística multivariada aplicada, $2^{\mathrm{a}}$ ed. Edições Silabo Ltda, Lisboa, 2001. 343 p.
OLIVEIRA, L. M. T., Estudo das regiões fitoecológicas brasileiras pela FAPAR/NDVI e relações com séries temporais de dados pluviométricos. Tese (D.Sc. Ciências Atmosféricas em Engenharia) Universidade Federal do Rio de Janeiro, COPPE, Rio de Janeiro, 208 p., 2008.

REIS, M. H. et al. Espacialização de dados de precipitação e avaliação de interpoladores para projetos de drenagem agrícola no estado de Goiás e Distrito Federal. In: SIMPÓSIO BRASILEIRO DE SENSORIAMENTO REMOTO 12. Goiânia. 2005, Anais, INPE, 2005. p. 229236 